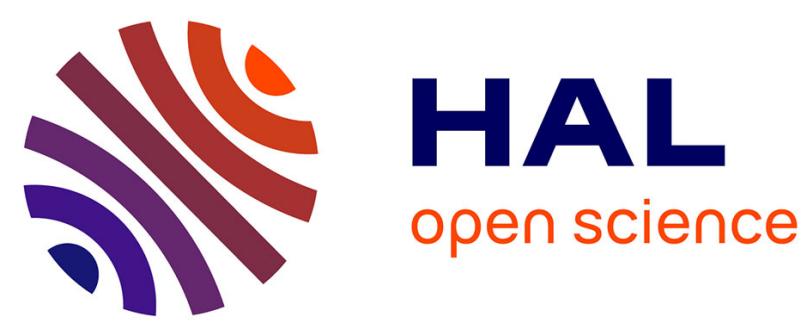

\title{
Therapy modifies cystine kidney stones at the macroscopic scale. Do such alterations exist at the mesoscopic and nanometre scale?
}

Dominique Bazin, Michel Daudon, Gilles André, Guy Matzen, Emmanuel Véron

\section{To cite this version:}

Dominique Bazin, Michel Daudon, Gilles André, Guy Matzen, Emmanuel Véron. Therapy modifies cystine kidney stones at the macroscopic scale. Do such alterations exist at the mesoscopic and nanometre scale?. Journal of Applied Crystallography, 2014, 47, pp.717 - 725. 10.1107/S1600576714004658 . hal-00992455

\section{HAL Id: hal-00992455 \\ https://hal.science/hal-00992455}

Submitted on 18 May 2014

HAL is a multi-disciplinary open access archive for the deposit and dissemination of scientific research documents, whether they are published or not. The documents may come from teaching and research institutions in France or abroad, or from public or private research centers.
L'archive ouverte pluridisciplinaire HAL, est destinée au dépôt et à la diffusion de documents scientifiques de niveau recherche, publiés ou non, émanant des établissements d'enseignement et de recherche français ou étrangers, des laboratoires publics ou privés. 
Journal of

Applied

Crystallography

ISSN 1600-5767

\section{Therapy modifies cystine kidney stones at the macroscopic scale. Do such alterations exist at the mesoscopic and nanometre scale?}

\section{Dominique Bazin, Michel Daudon, Gilles André, Raphael Weil, Emmanuel Véron and Guy Matzen}

J. Appl. Cryst. (2014). 47, 719-725

Copyright (C) International Union of Crystallography

Author(s) of this paper may load this reprint on their own web site or institutional repository provided that this cover page is retained. Republication of this article or its storage in electronic databases other than as specified above is not permitted without prior permission in writing from the IUCr.

For further information see http://journals.iucr.org/services/authorrights.html

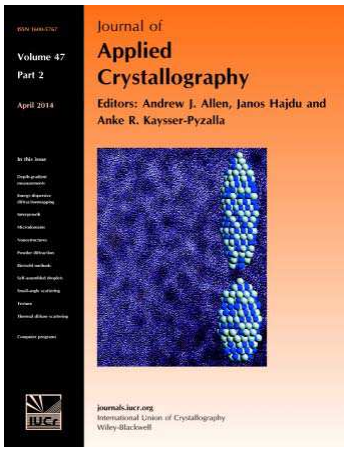

Many research topics in condensed matter research, materials science and the life sciences make use of crystallographic methods to study crystalline and non-crystalline matter with neutrons, X-rays and electrons. Articles published in the Journal of Applied Crystallography focus on these methods and their use in identifying structural and diffusioncontrolled phase transformations, structure-property relationships, structural changes of defects, interfaces and surfaces, etc. Developments of instrumentation and crystallographic apparatus, theory and interpretation, numerical analysis and other related subjects are also covered. The journal is the primary place where crystallographic computer program information is published.

Crystallography Journals Online is available from journals.iucr.org 
Journal of

Applied

Crystallography

ISSN 1600-5767

Received 18 August 2013

Accepted 28 February 2014

(C) 2014 International Union of Crystallography

\section{Therapy modifies cystine kidney stones at the macroscopic scale. Do such alterations exist at the mesoscopic and nanometre scale?}

\author{
Dominique Bazin, ${ }^{\mathrm{a} *}$ Michel Daudon, ${ }^{\mathrm{b}}$ Gilles André, ${ }^{\mathrm{c}}$ Raphael Weil, ${ }^{\mathrm{d}}$ Emmanuel \\ Véron ${ }^{\mathbf{e}}$ and Guy Matzen
}

\begin{abstract}
${ }^{a}$ CNRS, UPMC, Laboratoire de Chimie de la Matière Condensée de Paris, Collège de France, 11 place Marcelin Berthelot, 75231 Paris Cedex 05, France, ${ }^{\mathbf{b}}$ AP-HP, Hôpital Tenon, Service des Explorations Fonctionnelles, 4 rue de la Chine, 75970 Paris Cedex 20, France, 'Laboratoire Léon Brillouin (CEA-CNRS), Gif sur Yvette Cedex 91191, France, 'Laboratoire de Physique des Solides,

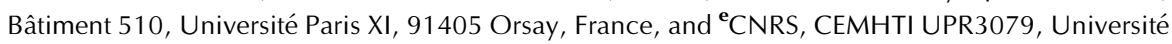
d'Orléans, 45071 Orléans, France. Correspondence e-mail: dominique.bazin@upmc.fr
\end{abstract}

\begin{abstract}
With an incidence of 1:7000 births, cystinuria, the most frequent cause of stone formation among genetic diseases, represents a major medical problem. Twentyfive cystine stones randomly selected from cystinuric patients were investigated. From a crystallographic point of view, cystine stones are composed of micrometre size crystallites, which are made up of an aggregation of nanocrystals. Through scanning electron microscopy, the morphology and size of the crystallites have been described, while the size of the nanocrystals was investigated by means of powder neutron diffraction. Powder neutron diffraction analysis and/or scanning electron microscopy examination of cystine stones provide evidence that usual alkalinization by sodium bicarbonate associated with high diuresis significantly reduces the size of both nanocrystals and crystallites, while for other treatments, including alkalinizing drugs and thiol derivatives, the data suggest mainly changes in the topology of crystallites. Alkalinization with sodium bicarbonate affects cystine kidney stones at the mesoscopic and nanoscopic scales, while other medical treatments only alter their surface. Such an approach may help to assess the interaction between drugs and cystine stones in cystinuric patients.
\end{abstract}

\section{Introduction}

Cystinuria comes from a mutation in renal epithelial cell transporters which induces a significant reduction in dibasic amino acids and cystine reabsorption and a high excretion of these amino acids, mainly lysine and cysteine (Dent \& Rose, 1974; Letavernier et al., 2012). Cystinuria represents a major medical problem because of stone recurrence and the risk to induce renal failure. Worldwide, its incidence is about 1:7000 births (Stephens, 1989; Barbey et al., 2000). It is the most frequent cause of stone formation among genetic diseases. Cystine stones represent about $1 \%$ of kidney stones in adults and they are more frequent in stone-forming children (accounting for up to 8\%) (Stapleton et al., 1987; Tekin et al., 2001). The disease expression as well as the incidence of cystine calculi vary with the genetic subtype (Goodyer et al., 1998; Gasparini et al., 1995). Owing to its poor solubility, cystine easily crystallizes in the nephrons and the urinary tract (Goldfarb et al., 2006; Brauers et al., 2006). Prevention of stone recurrence is based on high diuresis $\left(>31 \mathrm{~d}^{-1}\right)$, alkalinization by bicarbonate and/or citrate salts and, if needed, thiol derivatives which are able to form complexes with cysteine more soluble in urine than cysteine (Dolin et al., 2005). Observations of kidney stones through stereomicroscopy show that these therapies may modify at the macroscopic scale the morphology of calculi.

Thus, two morphological types of cystine kidney stones (KS), namely Va and Vb, may be distinguished (Bhatta et al., 1989; Daudon et al., 1993; Kim et al., 2005), on the basis of their surface characteristics as observed through a stereomicroscope. As previously described, the surface of the first kind of stones (type Va, Fig. 1a) is homogeneous, either granular, made of crystals with blunted angles, or only embossed. This morphology is commonly observed in untreated cystinuric patients. When cystinuria is treated with alkali or/and thiol therapy, a second type of cystine KS may appear (type Vb, Fig. 1b). In our experience, all Vb KS were observed in recurrent stone patients who had been treated using alkalinizing agents (unpublished data). These $\mathrm{Vb}$ KS exhibit a homogeneous, microcrystalline and smooth surface. Note that some treated patients may also produce Va calculi. These morphological types $\mathrm{Va}$ and $\mathrm{Vb}$ are in agreement with other reports which suggest that rough and smooth types have different behaviour when the stones are submitted to extra- 
corporeal shockwave lithotripsy (ESWL), the former being more easily fragmented by ESWL (Bhatta et al., 1989).

Most reports on cystinuria have been devoted to the genetic aspect or medical management (Pras, 2004; Dello Strologo et al., 2002) but no study has investigated the structural parameters of cystine stones. Such structural characterization on pathological calcifications (Bazin, Daudon et al., 2012; Bazin \& Daudon, 2012) can be performed either through various classical physical techniques (Evan et al., 2007; Rao et al., 2011; Bazin et al., 2006), such as scanning electron microscopy (SEM) (Gràcia-Garcia et al., 2011; Dessombz, Méria et al., 2011, 2012), micro-computerized tomography (Williams et al., 2012; Kaiser et al., 2011), Fourier transform infrared (FTIR) and Raman spectroscopy (Quy Dao \& Daudon, 1997; Estepa \& Daudon, 1998; Guerra-Lopez et al., 2008; Wilson et al., 2010), proton induced X-ray emission (Pineda-Vargas et al., 2009), and laser ablation methods (Stepankova et al., 2013), or through techniques specific to large instruments, such as micro X-ray fluorescence (Bazin et al., 2007), micro X-ray absorption spectroscopy (Bazin et al., 2009; Carpentier et al., 2010; Nguyen et al., 2011), micro FTIR spectroscopy (Dessombz, Bazin et al., 2011) or neutron scattering (Bazin, André et al., 2012).

The aim of this article is to relate morphological differences observed at the macroscopic scale induced by the therapy to structural characteristics at the mesoscopic and/or at the nanometre scale. Such correlation has been established recently for very particular whewellite kidney stones linked to another genetic disease, namely primary hyperoxaluria (Daudon et al., 2008; 2009). To attain this goal, a structural investigation through SEM and powder neutron diffraction (PND) has been performed. At this point, we introduce the terms of nanocrystals and crystallites as defined by Van
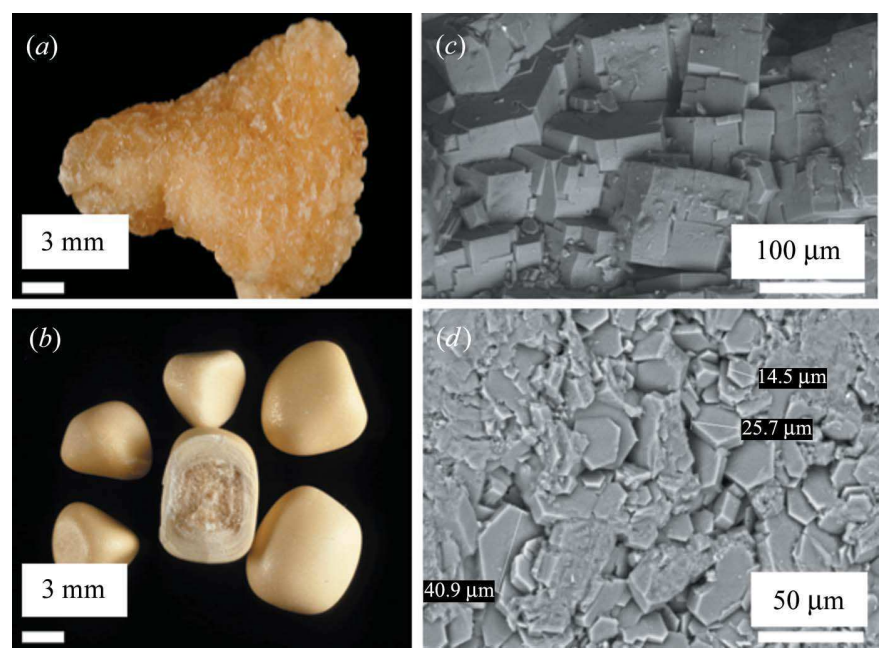

\section{Figure 1}

(a) Va cystine kidney stone, (b) Vb cystine kidney stones. The cross section of a stone reveals a diffuse concentric structure in the periphery and an unorganized agglomerate of cystine crystals in the core. (c) SEM image of a typical Va cystine kidney stone made of large crystals exhibiting flat surfaces with well defined corners and edges. The stone was removed from the kidney of an untreated patient. (d) SEM image of a Vb kidney stone.
Meerssche \& Feneau-Dupont (1973) in order to describe the hierarchical structure of these pathological concretions. Crystallites (measuring typically some tens of micrometres) are made up of a collection of nanocrystals (measuring typically some hundreds of nanometres).

SEM gave us the opportunity to perform a direct observation of the morphology and the size of the crystallites at the micrometre scale (Carpentier et al., 2009; Bazin, André et al., 2012). At the nanometre scale, the average size of the nanocrystals present in the crystallites was obtained through PND (Bazin et al., 2006; Daudon et al., 2009; Bazin, André et al., 2012).

\section{Materials and methods}

The biological samples (Table 1) analysed in the present investigation came from Tenon Hospital. Regarding ethics, we follow the usual procedures (Dessombz, Bazin et al., 2011; Dessombz et al., 2012). All participants (adults or parents of children participating in the study) gave their verbal consent, documented by the researchers, for use of the material. Samples were examined without knowledge of the name of the patient or other identifying data. Ethical approval for the study was obtained from the ethics committee of Tenon Hospital. The investigation conformed to the principles of the Declaration of Helsinki.

Twenty-five cystine KS were selected according to the following criteria: (1) the stone material had to be large enough (more than $30 \mathrm{~mm}^{3}$ ) to allow successive measurements including sequential infrared analysis, SEM examination and PND analysis; (2) clinical information had to be available regarding sex and age of the patient, stone recurrence, and accurate information on medical therapy. Stones from patients who had received successive medical treatments including alkalinizing drugs and/or thiol derivatives were excluded. All the samples were first investigated by stereomicroscopy and FTIR spectroscopy (Quy Dao \& Daudon, 1997; Estepa \& Daudon, 1998). All of them were examined by SEM while 24 samples were studied by PND. Selected clinical data from the patients whose samples were studied have been gathered in Table 1.

An FEI/Philips XL40 environmental scanning electron microscope was used for characterization of the samples. An important feature of the environmental scanning electron microscope compared to a conventional scanning electron microscope is the fact that nonconductive materials can be imaged without any conductive coating, which permits a direct observation with no damage for the sample. Imaging was performed with a gaseous secondary electron detector, an accelerating voltage of $20 \mathrm{kV}$ and a water pressure of 0.4 torr $(53.3 \mathrm{~Pa})$ in the chamber.

Neutron diffraction diagrams were collected on the G4.1 diffractometer at Laboratoire Léon Brillouin at room temperature. This beamline is equipped with a two-axis powder diffractometer with a vertical focusing pyrolytic graphite monochromator and an 800-cell multidetector covering an $80^{\circ} 2 \theta$ range (step $0.1^{\circ}$ between two cells). More 
Table 1

Clinical data on selected samples.

MSR $=$ multiple stones recurrences. NA $=$ not assessed.

\begin{tabular}{|c|c|c|c|c|c|c|}
\hline Sample & Sub-type & Sex & Age & Therapy & Clinical data & Crystal size $(\mathrm{nm})$ \\
\hline \multicolumn{7}{|c|}{ Untreated patients } \\
\hline 1 & $\mathrm{Va}$ & $\mathrm{M}$ & 29 & No treatment & MSR & Above 200 \\
\hline 2 & Va & M & 28 & No treatment & $\begin{array}{l}\text { MSR. No diagnostic } \\
\text { before stone analysis }\end{array}$ & Above 200 \\
\hline 3 & $\mathrm{Va}$ & M & 26 & No treatment & $\begin{array}{l}\text { 1st stone episode (bilat- } \\
\text { eral kidney stones) }\end{array}$ & Above 200 \\
\hline 4 & $\mathrm{Va}$ & $\mathrm{F}$ & 3 & No treatment & 1st stone & Above 200 \\
\hline 5 & $\mathrm{Va}$ & M & 25 & No treatment & MSR & Above 200 \\
\hline 6 & $\mathrm{Va}$ & $\mathrm{M}$ & 25 & No treatment & MSR & Above 200 \\
\hline 7 & Va & M & 40 & No treatment & MSR & Above 200 \\
\hline \multicolumn{7}{|c|}{ Alkalinization with sodium bicarbonate } \\
\hline 8 & $\mathrm{Vb}$ & $\mathrm{M}$ & 23 & Sodium bicarbonate & MSR & $72 \pm 3$ \\
\hline 9 & $\mathrm{Vb}$ & $\mathrm{F}$ & 41 & Sodium bicarbonate & $\begin{array}{l}\text { MSR. Previous } \\
\text { nephrectomy }\end{array}$ & $94 \pm 6$ \\
\hline 10 & $\mathrm{Vb}$ & M & 34 & Sodium bicarbonate & MSR & $147 \pm 10$ \\
\hline 11 & $\mathrm{Vb}$ & $\mathrm{F}$ & 52 & $\begin{array}{l}\text { Sodium bicarbonate } \\
\text { (Vichy water) }\end{array}$ & $\begin{array}{l}\text { MSR. Destroyed right } \\
\text { kidney }\end{array}$ & $170 \pm 15$ \\
\hline \multicolumn{7}{|c|}{ Alkalinization with other salts } \\
\hline 12 & $\mathrm{Va}$ & $\mathrm{F}$ & 28 & $\begin{array}{l}\text { Foncitril (citric acid }+ \\
\text { sodium citrate }+ \\
\text { potassium citrate) }\end{array}$ & MSR & Above 200 \\
\hline 13 & $\mathrm{Va}$ & M & 19 & $\begin{array}{l}\text { Alcaphor (trometamol }+ \\
\text { disodium citrate }+ \\
\text { dipotassium citrate) }\end{array}$ & MSR & Above 200 \\
\hline 14 & $\mathrm{Va}$ & $\mathrm{F}$ & 3 & $\begin{array}{l}\text { Alcaphor }(\text { trometamol }+ \\
\text { disodium citrate }+ \\
\text { dipotassium citrate) }\end{array}$ & MSR & Above 200 \\
\hline 15 & Va & $\mathrm{F}$ & 27 & Potassium citrate & MSR & Above 200 \\
\hline \multicolumn{7}{|c|}{ Sulfhydryls } \\
\hline 16 & Va & $\mathrm{F}$ & 35 & Tiopronine & MSR & Above 200 \\
\hline 17 & $\mathrm{Va}$ & $\mathrm{F}$ & 25 & Tiopronine & MSR & Above 200 \\
\hline 18 & $\mathrm{Va}$ & $\mathrm{M}$ & 30 & Tiopronine & MSR & NA \\
\hline 19 & $\mathrm{Va}$ & $\mathrm{F}$ & 52 & Tiopronine & MSR & Above 200 \\
\hline 20 & Va & M & 19 & D-Penicillamine & MSR & Above 200 \\
\hline 21 & Va & $\mathrm{F}$ & 36 & D-Penicillamine & MSR & Above 200 \\
\hline 22 & $\mathrm{Va}$ & M & 30 & D-Penicillamine & MSR. Kidney atrophy & Above 200 \\
\hline 23 & $\mathrm{Va}$ & $\mathrm{M}$ & 26 & Captopril & MSR & Above 200 \\
\hline 24 & $\mathrm{Va}$ & $\mathrm{M}$ & 26 & Captopril & MSR & Above 200 \\
\hline 25 & $\mathrm{Va}$ & $\mathrm{M}$ & 48 & Captopril & MSR & Above 200 \\
\hline
\end{tabular}

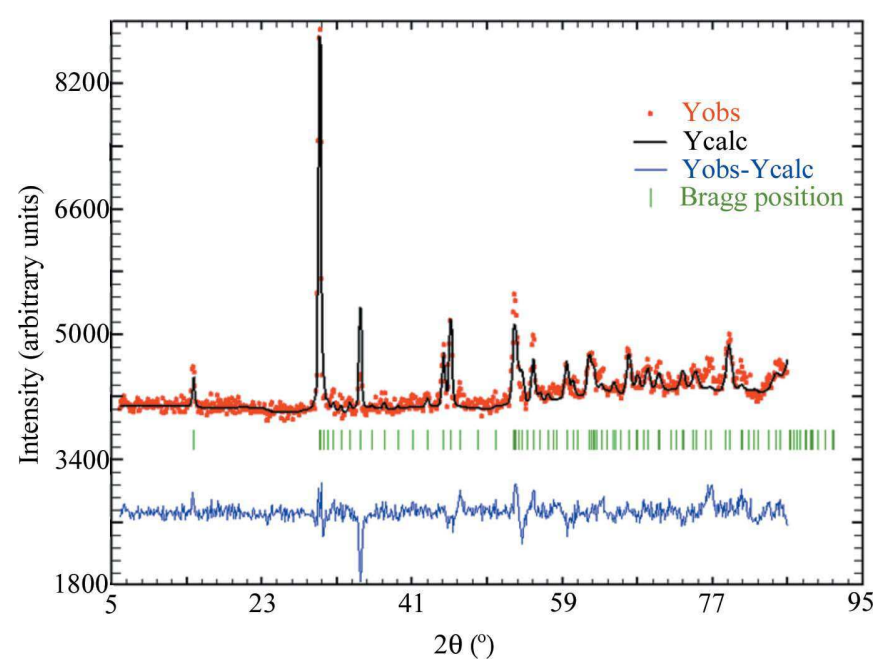

Figure 2

Typical final observed (Yobs in red), calculated (Ycalc) and difference profiles (Yobs-Ycalc in blue) of the PND diagram of a cystine kidney stone. Tick marks (Bragg position in green) below the profiles indicate the peak positions of allowed Bragg reflections for cystine. precisely, neutron diffraction diagrams were collected using a wavelength of $2.4226 \AA$, with an acquisition time of a few hours on samples without any preparation. Then the mean size of the crystals for each sample (Fig. 2) was calculated using the FullProf program (Rodríguez-Carvajal, 2001; Dahaoui et al., 1999). More precisely the apparent mean size of the coherently diffracting crystals was extracted from the observed broadened Bragg peaks of the PND stone diagrams taking into account the instrumental resolution function of the neutron diffractometer. The FullProf program provided a value of this mean size with its standard deviation.

The size of the crystallites (measured using the environmental scanning electron microscope) in micrometres is expressed as mean $\pm \mathrm{SE}$ (standard error). In order to obtain a significant average size for the crystallites, the complete set of observations performed on the different samples has been considered. For each observation, we consider all crystallites for which we measure a size. In Fig. 2, we show a typical set of measurements. The size of the nanocrystals (measured through PND) is expressed in nanometres as mean \pm SE. All statistical comparisons were performed using the Mann-Whitney test or Student $\mathrm{t}$ test for continuous variables. Statistical significance was defined as a $p$ value less than 0.05 .

\section{Results}

A first investigation through SEM was performed on a set of samples coming from seven untreated patients (patients 1-7 in Table 1). As an example, the SEM image in Fig. 1(c) shows a typical cystine stone (untreated patient) made of large crystals exhibiting flat surfaces with well defined corners and edges, a result in line with the hexagonal structure of cystine. At the opposite extreme, the typical morphology of crystallites coming from patients treated with sodium bicarbonate in our series (patients 8-11 in Table 1) is less well defined (Fig. 1d). Moreover, from a more detailed inspection of Figs. $1(c)$ and $1(d)$, a significant difference was observed regarding the size of hexagonal plates (75.5 $\pm 12.2 \mu \mathrm{m}$ versus $23.5 \pm 2.8 \mu \mathrm{m}, p=0.0004)$.

Figs. 3( $a)$ and 3(b) illustrate two examples of SEM micrographs of stones observed in patients receiving either Foncitril (Fig. $3 a$ ) or Alcaphor (Fig. 3b) as alkalinization therapy. Note that cystine crystals seem poorly affected by the latter treatment.

Finally, cystine KS coming from patients treated with thiol derivatives (tiopronine, D-penicillamine, captopril) have been 
examined also through SEM (Figs. $4 a, 4 b$ and $4 c$, respectively). Some significant differences exist regarding the surfaces of these cystine KS, suggesting some signs of cystine crystal dissolution for tiopronine- or D-penicillamine-treated patients but not for stones in patients under captopril therapy.

The structural parameters determined for the biological samples show little deviation from those already published (Dahaoui et al., 1999). For the seven untreated patients (subjects 1-7, Table 1), the mean size of the nanocrystals was above $200 \mathrm{~nm}$, the upper limit for our experimental setup. Conversely, for the patients treated with alkalinization by sodium bicarbonate, the mean size of the nanocrystals was significantly lower $(138 \mathrm{~nm}, p=0.003)$ and ranged from 70 to $170 \mathrm{~nm}$ (subjects 8-11, Table 1). It is of note that all the corresponding stones exhibit a $\mathrm{Vb}$ type. Finally, stones from all patients treated with other alkalinizing drugs (subjects 12-15, Table 1) or with thiol derivatives (subjects 16-25) were composed of cystine nanocrystals above $200 \mathrm{~nm}$. The stone type was Va in all cases.

\section{Discussion}

Although cystine is known as only one crystalline phase in urine, two different stone morphologies, $\mathrm{Va}$ and $\mathrm{Vb}$, have been described in patients, with two different behaviours when treated by ESWL (Bhatta et al., 1989; Daudon et al., 1993). To explain this difference, we investigated the structural characteristics of these two types of stones at the macroscopic, mesoscopic and nanometric scales.

At the macroscopic scale, the average size of Va KS coming from treated or untreated patients was (mean \pm standard deviation) $8.9 \pm 6.1 \mathrm{~mm}$ (range $0.8-39 \mathrm{~mm}$ ) versus $4.9 \pm$ $2.5 \mathrm{~mm}$ (range $1.5-11 \mathrm{~mm}$ ) for $\mathrm{Vb} \mathrm{KS}$ from treated patients

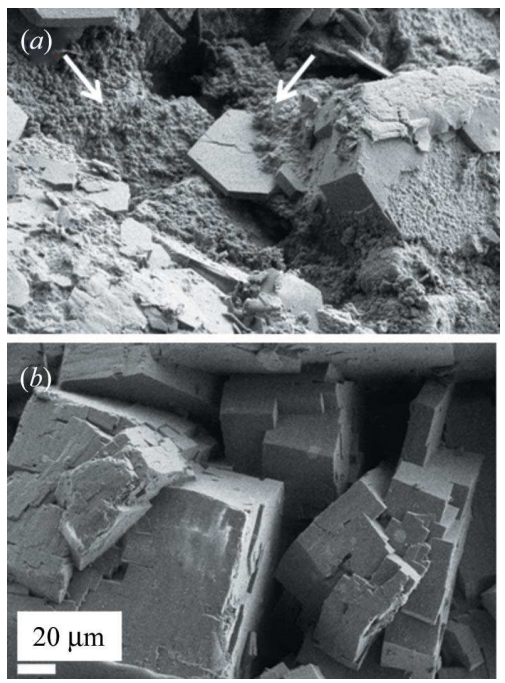

\section{Figure 3}

(a) SEM image of a cystine stone from a patient treated with Foncitril. We can see the coexistence of well defined cystine crystals with a plane surface and altered crystals with a rough surface. Note the presence of deposited spherical particles of apatite (arrows) as a consequence of the increased $\mathrm{pH}$ in urine owing to therapy. (b) Poorly affected cystine crystals in a patient treated with Alcaphor. The crystal edges are still well defined, suggesting a limited effect of the treatment. $(p<0.001)$. Considering that the maximum size for spontaneous passage of stones is around $6 \mathrm{~mm}$, this difference in stone size could be clinically very important because Vb-type stones, owing to their reduced dimensions, may easily pass without any urological procedures while Va stones often require urological treatment. Indeed, in our experience, based on 730 cystine stones analysed in our laboratory, $\mathrm{Vb}$ stones are about ten to 20 times less frequent than Va stones, and the latter stone type may also be observed in patients treated long term with sodium bicarbonate. In fact, we identified four patients who formed $\mathrm{Va}$ stones while receiving only that treatment. Unfortunately, their stones or fragments were too small to allow us to apply all of our analytical procedures on the same sample as done in the present work.

At the mesoscopic scale, a significant difference in mean crystallite size was observed between Va stones from treated and untreated patients and $\mathrm{Vb}$ stones from treated patients (75.5 versus $23.5 \mu \mathrm{m}, p=0.0004$ ). Finally, at the nanometric scale, the mean size of nanocrystals was significantly lower for $\mathrm{Vb}$ stones (138 versus more than $200 \mathrm{~nm}$ for Va stones). Thus, as a preliminary conclusion, the complete set of data shows that, from nanometric to macroscopic scales, $\mathrm{Vb}$ and $\mathrm{Va}$ stones seem to be significantly different.
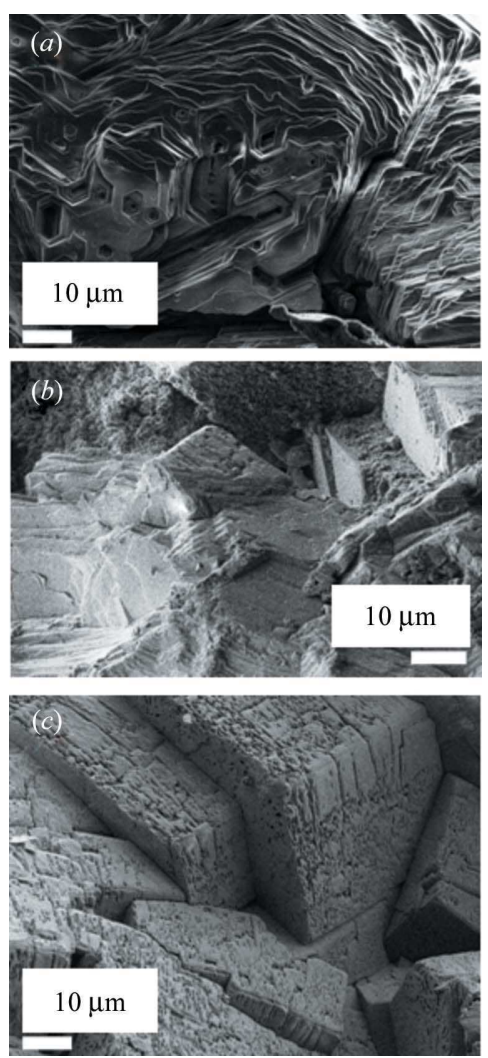

Figure 4

(a) Significant erosion of the surface of cystine crystals in a patient treated with tiopronine. Note the hexagonal holes which correspond to dissolved small cystine crystals. Large ones have lost their typical hexagonal shape. (b) Similar alteration of the cystine crystals in a stone from a patient treated with D-penicillamine as observed with tiopronine. (c) Example of impaired surface of cystine crystals displaying numerous scattered holes similar to wormholes in a stone from a patient treated with captopril. The bulk of the crystals is not affected by such a treatment. 
The second major finding of this investigation was the observation of different alterations of the crystal surface at the mesoscopic scale related to the medical treatment. In the case of Foncitril (patient 12), Fig. 3(a) exhibits at the same time well defined cystine crystals with a plane surface and altered crystals with a rough surface. Note the presence of deposited spherical particles of apatite (arrow) as a consequence of the increased $\mathrm{pH}$ in urine resulting from therapy. For patients 13 and 14, treated with Alcaphor, the crystal edges are still well defined, suggesting a limited effect of the treatment (Fig. 3b).

Regarding patients treated with thiol derivatives, another kind of erosion was observed at the surface of cystine crystals (Fig. 4). In patients treated with tiopronine (subjects 16-19, Fig. 4a), hexagonal holes were observed, which seem to correspond to dissolved small cystine crystals. It is of note that the large crystals have lost their typical hexagonal shape, also suggesting the beginning of a dissolution process. Such dissolution of cystine stones has already been reported (suggested) in the literature (Lotz \& Bartter, 1965; Lindell et al., 1995). Similar alterations of cystine crystals as seen with tiopronine were observed for patients (subjects 20-22, Fig. 4b) treated with D-penicillamine. Because the patient also received recommendation for alkalinizing his or her urine, small spherical entities made of carbapatite as indicated by FTIR spectroscopy are also present in the stone. Finally, even if it seems that the bulk of the crystals is not affected by captopril therapy (subjects 23-25, Fig. 4c), the impaired surfaces of the cystine crystals display numerous scattered holes similar to wormholes. The limited effect of captopril on cystine crystals in comparison to that observed for tiopronine and D-penicillamine is in agreement with clinical findings suggesting the failure of captopril in preventing stone recurrence (Aunsholt \& Ahlbom, 1990). Indeed, in our crystalluria studies, we were unable to demonstrate any significant effect of captopril for reducing cystine crystal volume, while a significant decrease in crystal volume was observed in patients treated by either tiopronine or D-penicillamine (Daudon et al., 2003). It is well known that tiopronine and D-penicillamine are able to form soluble complexes with cysteine, thus reducing significantly the amount of cysteine available to form cystine in urine (Meiouet et al., 2011). As a consequence, the relative supersaturation for cystine is significantly reduced and cystine solubility improved (Asplin \& Asplin, 2012), especially if, in addition, the urine volume is significantly increased (above $3 \mathrm{ld}^{-1}$ ) along with urine $\mathrm{pH}(\mathrm{pH} \geq 7.5)$, thus allowing previously formed crystals to dissolve at least to a certain extent.

Thus, at the nanometric scale, PND shows that the nanocrystal's size is lower for patients under classical alkalinization based on sodium bicarbonate than for untreated patients and patients treated with any other drug including thiol derivatives or alkalizing drugs such as trometamol or citrate salts. Thus, a first salient point of this study lies in the fact that only the usual alkaline therapy significantly reduces the growing process of cystine crystals. As underlined previously (Tiselius, 2010), high urine $\mathrm{pH}$ seems to be a key point for preventing stone recurrence. This is in agreement with our studies on cystine crystalluria related to urine $\mathrm{pH}$ : the higher the urine $\mathrm{pH}$, the lower the crystal volume of cystine in urine. Moreover, we have already shown that all patients with a high crystal volume of cystine in urine (above $3000 \mu \mathrm{m}^{3} \mathrm{~mm}^{-3}$ ), which corresponds to large crystallite aggregates, developed new stones, while patients with a lower crystal volume did not (Daudon et al., 2003).

Citrate salts would not be able to sufficiently increase urine $\mathrm{pH}$ to effectively reduce crystal growth by comparison with bicarbonate salts. At this point of the discussion, it is worth underlining that the medical therapy based on high fluid intake, alkalinization or thiol administration may be considered as a cyclic process. Each administration of the alkalinizing drug results in a significant but temporary increase in urine $\mathrm{pH}$, both in the different parts of the nephron and in the final urine, followed by a subsequent slow decrease up to the next intake of the drug. It is the same for the dilution of the urine following water intake. As a result of this cycle, the cystine saturation is varying in urine, with other factors such as diet and metabolism also influencing its excretion. Thus, it may be difficult to avoid crystal formation over extended periods of time. As a consequence, stone recurrence is a frequent finding in cystinuric patients while under medical therapy, because it is not so easy to optimize day-to-day water intake, urine $\mathrm{pH}$ and diet. Perhaps Vb stones with small nanocrystals and crystallites are observed only in the most compliant patients able to maintain urine $\mathrm{pH}$ in the highest range. However that may be, our findings suggest that therapeutic measures are able to modify the structural characteristics of cystine KS.

As recently reported by Asplin \& Asplin (2012), the efficacy of thiol derivatives requires high urine $\mathrm{pH}$, underlining the clinical benefit of simultaneous treatment by alkalinizing agents and thiol derivatives rather than by sulfhydryl alone. Promising results provided by Rimer and coworkers suggest that L-cystine methyl esters could be efficient molecules able to reduce cystine crystal formation (Rimer et al., 2010). In vivo studies remain to be performed in order to validate the results and assess potential side effects.

On the basis of current medical treatment, our study by SEM examination has pointed out significant differences in the average size of the crystallites between untreated patients and patients treated with alkalinization. The complete set of structural results shows that the usual alkalinization process not only reduces the size of the cystine nanocrystals as shown by PND but also limits their agglomeration, i.e. the size of the crystallites is finally smaller. These results clearly demonstrate the effect of alkalinization by sodium bicarbonate in cystinuric patients. Is it a real benefit to form $\mathrm{Vb}$ rather than Va stones? Although smaller in size, $\mathrm{Vb}$ stones are often more numerous than Va stones (9.1 versus 5.5 per patient). As a consequence, spontaneous and easy passage of the stones cannot be guaranteed. Nevertheless, the change from $\mathrm{Va}$ to $\mathrm{Vb}$ stones is highly suggestive of the benefit of therapy on crystal formation, which is a prerequisite to reduce stone recurrence.

On the other hand, thiol therapy based on tiopronine or D-penicillamine, not on captopril treatment, seems able to help in solubilizing cystine crystals, at least in part, suggesting 
the potential in clinical practice to combine alkalinization and thiol derivatives. Because of the reduced agglomeration of the crystallites, we can expect also a decrease in the size of KS and a facilitation of their spontaneous passage. As underlined above, we observed a significantly reduced size of stones in such treated patients when compared with other therapies.

If the $\mathrm{Vb}$ stone type is a benefit for the patient is another question. First, because all $\mathrm{Vb}$ stones were found as recurrent stones in treated patients, they may be considered as a failure of medical therapy. Second, this stone type appears to be infrequent. Nevertheless, what we can conclude from our investigations is that different effects on cystine crystals may be observed according to the treatment. However, an important limitation in our results is that we cannot ensure the actual compliance of the patients regarding the proposed drugs, especially over months or years. The high recurrence rate of stones in medically managed cystinuric patients as previously reported (Barbey et al., 2000) is highly suggestive of a poor compliance of the patients despite evidence for a significant beneficial effect of the treatment.

\section{Conclusions}

In agreement with the results reported for ESWL treatment, SEM examination and PND analysis provide evidence that significant structural differences exist between $\mathrm{Va}$ and $\mathrm{Vb}$ kidney stones at different scales. Moreover, among the different medical treatments, alkalinization with sodium bicarbonate seems to affect cystine kidney stones at the micrometre and nanometre scales, reducing the size of both nanocrystals and crystallites, while other medical treatments only alter the surface of the crystallites. Even though the number of patients is small (25), the results provide evidence that the various treatments are associated with very different modifications in the cystine crystal surface. Thus, such an approach helps to assess the interaction between drugs and cystine stones and is more generally applicable to the study of pathological calcifications.

This research was supported by the physics and chemistry institutes of Centre National de la Recherche Scientifique and by contract ANR-09-BLAN-0120-02. The authors are grateful to the Leon Brillouin laboratory for beamtime allocation.

\section{References}

Asplin, D. M. \& Asplin, J. R. (2012). J. Urol. 187, 1282-1286. Aunsholt, N. A. \& Ahlbom, G. (1990). Clin. Nephrol. 34, 92-93.

Barbey, F., Joly, D., Rieu, P., Méjean, A., Daudon, M. \& Jungers, P. (2000). J. Urol. 163, 1419-1423.

Bazin, D., André, G., Weil, R., Matzen, G., Véron, E. \& Daudon, M. (2012). Urology, 79, 786-790.

Bazin, D., Carpentier, X., Brocheriou, I., Dorfmuller, P., Aubert, S., Chappard, C., Thiaudière, D., Reguer, S., Waychunas, G., Jungers, P. \& Daudon, M. (2009). Biochimie, 91, 1294-1300.
Bazin, D., Chevallier, P., Matzen, G., Jungers, P. \& Daudon, M. (2007). Urol. Res. 35, 179-184.

Bazin, D. \& Daudon, M. (2012). J. Phys. D Appl. Phys. 45, 383001.

Bazin, D., Daudon, M., Chevallier, P., Rouziere, S., Elkaim, E., Thiaudière, D., Fayard, B., Foy, E., Albouy, P. A., Andre, G., Matzen, G. \& Véron, E. (2006). Ann. Biol. Clin. 64, 125-139.

Bazin, D., Daudon, M., Combes, C. \& Rey, C. (2012). Chem. Rev. 112, 5092-5120.

Bhatta, K. M., Prien, E. L. \& Dretler, S. P. (1989). J. Urol. 142, $937-$ 940.

Brauers, E., Hozyasz, K. \& Golabek, B. (2006). J. Ped. Urol. 2, 575578.

Carpentier, X., Bazin, D., Jungers, P., Reguer, S., Thiaudière, D. \& Daudon, M. (2010). J. Synchrotron Rad. 17, 374-379.

Carpentier, X., Daudon, M., Traxer, O., Jungers, P., Mazouyes, A., Matzen, G., Véron, E. \& Bazin, D. (2009). Urology, 73, 968975.

Dahaoui, S., Pichon-Pesme, V. \& Howard, J. A. K. (1999). J. Phys. Chem. A, 103, 6240-6250.

Daudon, M., Bader, C. A. \& Jungers, P. (1993). Scanning Microsc. 7, 1081-1106.

Daudon, M., Bazin, D., André, G., Jungers, P., Cousson, A., Chevallier, P., Véron, E. \& Matzen, G. (2009). J. Appl. Cryst. 42, 109-115.

Daudon, M., Cohen-Solal, F., Barbey, F., Gagnadoux, M. F., Knebelmann, B. \& Jungers, P. (2003). Urol. Res. 31, 207-211.

Daudon, M., Jungers, P. \& Bazin, D. (2008). New Engl. J. Med. 359, $100-102$.

Dello Strologo, L. et al. (2002). J. Am. Soc. Nephrol. 13, $2547-$ 2553.

Dent, C. C. \& Rose, G. A. (1974). J. Med. New Ser. 214, 507-512.

Dessombz, A., Bazin, D., Dumas, P., Sandt, C., Sulé-Suso, J. \& Daudon, M. (2011). PLoS ONE, 6, e28007.

Dessombz, A., Méria, P., Bazin, D. \& Daudon, M. (2012). PLos ONE, 7, e51691.

Dessombz, A., Méria, P., Bazin, D., Foy, E. \& Rouzière, S. (2011). Prog. Urol. 21, 940-945.

Dolin, D. J., Asplin, J. R., Flagel, L., Grasso, M. \& Goldfarb, D. S. (2005). J. Endourol. 19, 429-432.

Estepa, L. \& Daudon, M. (1998). Biospectroscopy, 3, 347-369.

Evan, A. P., Lingeman, J. E. \& Williams, J. C. (2007). AIP Conf. Proc. 900, 1-460.

Gasparini, P. et al. (1995). Am. J. Hum. Genet. 57, 781-788.

Goldfarb, D. S., Coe, F. L. \& Asplin, J. R. (2006). Kidney Int. 69, 10411047.

Goodyer, P., Saadi, I., Ong, P., Elkas, G. \& Rozen, R. (1998). Kidney Int. 54, 56-61.

Gràcia-Garcia, S., Millán-Rodríguez, F., Rousaud-Barón, F., Montanés-Bermúdez, R., Angerri-Feu, O., Sánchez-Martín, F., Villavicencio-Mavrich, H. \& Oliver-Samper, A. (2011). Actas Urol. Esp. 35, 354-362.

Guerra-Lopez, J. R., Guida, J. A., Della Vedova, C. O. \& Garcia, R. R. (2008). Acta Bioquim. Clin. Latinoamericana, 42, 189-193.

Kaiser, J., Hola, M., Galiova, M., Novotny, K., Kanicky, V., Martinec, P., Scucka, J., Brun, F., Sodini, N., Tromba, G., Mancini, L. \& Koristkova, T. (2011). Urol. Res. 39, 259-267.

Kim, S. C., Hatt, E. K., Lingeman, J. E., Nadler, R. B., Mcateer, J. A. \& Williams, J. C. Jr (2005). J. Urol. 174, 1468-1471.

Letavernier, E., Traxer, O., Haymann, J. P., Bazin, D. \& Daudon, M. (2012). Prog Urol FMC, 22, F119-F123.

Lindell, A., Denneberg, T. \& Jeppsson, J. O. (1995). Nephron, 71, 328 342.

Lotz, M. \& Bartter, F. C. (1965). Brit. Med. J. 2, 1408-1409.

Meiouet, F., El Kabbaj, S. \& Daudon, M. (2011). Prog. Urol. 21, 40 47.

Nguyen, C., Ea, H. K., Thiaudiere, D., Reguer, S., Hannouche, D., Daudon, M., Lioté, F. \& Bazin, D. (2011). J. Synchrotron Rad. 18, 475-480. 
Pineda-Vargas, C. A., Eisa, M. E. M. \& Rodgers, A. L. (2009). Appl. Rad. Isot. 67, 464-469.

Pras, E. (2004). Mol. Urol. 4, 409-414.

Quy Dao, N. \& Daudon, M. (1997). Infrared and Raman Spectra of Calculi. Paris: Elsevier.

Rao, N. P., Preminger, G. M. \& Kavanagh, J. P. (2011). Urinary Tract Stone Disease. London: Springer.

Rimer, J. D., An, Z., Zhu, Z., Lee, M. H., Goldfarb, D. S., Wesson, J. A. \& Ward, M. D. (2010). Science, 330, 337-341.

Rodríguez-Carvajal, J. (2001). IUCr Commission on Powder Diffraction Newsletter, No. 26, pp. 12-19.

Stapleton, F. B., McKay, C. P. \& Noe, H. N. (1987). Pediatr. Ann. 16, 980-984.
Stepankova, K., Novotny, K., Galiova, M. V., Kanicky, V., Kaiser, J. \& Hahn, D. W. (2013). Spectrochim. Acta Part B, 81, 43-49.

Stephens, A. D. (1989). J. Inher. Metab. Dis. 12, 197-209.

Tekin, A., Tekgul, S., Atsu, N., Sahin, A. \& Bakkaloglu, M. (2001). J. Urol. 165, 2328-2330.

Tiselius, H. G. (2010). Curr. Opin. Urol. 20, 169-173.

Van Meerssche, M. \& Feneau-Dupont, J. (1973). Introduction à la Cristallographie et à la Chimie Structurale. Louvain: Vander.

Williams, J. C., Hameed, T., Jackson, M. E., Aftab, S., Gambaro, A., Pishchalnikov, Y. A., Lingeman, J. E. \& McAteer, J. A. (2012). J. Urol. 188, 996-1001.

Wilson, E. V., Junaid, B. M. \& Vaidyana, V. K. (2010). Spectrochim. Acta Part A, 77, 442-445. 